\title{
Timely initiation of complementary feeding and associated factors among children aged 6 to 12 months in Northern Ethiopia: an institution-based cross-sectional study
}

Ashenafi Shumey ${ }^{1 *}$, Meaza Demissie ${ }^{2+}$ and Yemane Berhane ${ }^{2+}$

\begin{abstract}
Background: Exclusive breastfeeding (EBF) for the first six months of life is critical for the wellbeing of the child. In the mean while, timely initiation and starting nutritionally-adequate, safe, age-appropriate complementary feeding at six months is recommended for the better health and development of infants. According to the Ethiopian Demographic and Health Survey 2011, timely initiation of complementary feeding in Ethiopia at the 6th month was only $51 \%$. The purpose of this study is to determine the magnitude of timely initiation of complementary feeding and associated factors in Mekelle town, Northern Ethiopia.
\end{abstract}

Methods: An institutional based cross-sectional study design was conducted among 422 mothers of infants aged from six months to one year selected from six public health facilities. Sample size proportional to the patient flow rate of each institution was allocated and systematic random sampling method was used to get the study participant. An exit interview using structured questionnaire was conducted about their experience on complementary feeding and related experience. The questionnaire was pretested among 21 mothers. Data were entered with EPI info version 3.5.1 and cleaning and analysis was done by using SPSS version 16. Frequencies distribution, binary and multiple logistic regressions were done. OR and 95\% confidence interval was computed.

Result: The prevalence of timely initiation of complementary feeding at sixth month was 62.8\% (265/422, 95\% C.I: 58.1, 67.31\%). Educational level, occupation of mother, parity, having ANC follow up, and birth preparedness were found to be independent predictor of timely initiation of complementary feeding.

Conclusions: Almost two-third of mothers initiated complementary feeding at six month of child' age as recommended. This was relatively higher prevalence than most developing countries. However, significant proportion of mothers still did not initiate complementary feeding timely. Mothers who are illiterate and completed only primary school need more attention. All mothers must be encouraged to make antenatal care follow up.

Keywords: Timely initiation, Complementary feeding, Ethiopia

\footnotetext{
* Correspondence: ashureech@yahoo.com

${ }^{\dagger}$ Equal contributors

${ }^{1}$ Public Health Department, College of Health Sciences, Mekelle University,

Mekelle, Ethiopia

Full list of author information is available at the end of the article
} 


\section{Background}

Complementary feeding is giving infants other foods or fluids in addition to the breast milk at six months age of child [1]. Adequate nutrition during infancy and early childhood is critical to the development of children's full human potential. Exclusive breastfeeding is critical and adequate for the first six months of child. However; after six months breast milk alone is no longer sufficient to meet late infant's nutritional requirements and, therefore, timely starting nutritionally-adequate, safe, ageappropriate complementary feeding at sixth month of age is recommended for better health and development of infants [2-8]. According to the Ethiopian Demographic and Health Survey 2011, timely initiation of complementary feeding in Ethiopia at the 6th month was only $51 \%$ [9] which was $10 \%$ in Nairobi, $50 \%$ in Taiwan and $55.1 \%$ in West Bengal India [10-12].

The estimated infant mortality for Ethiopia have been 77 per 1000 live births for a long time, however, the current demographic and health survey reported a reduction in infant mortality which is 59 deaths per 1,000 live births [9]. It is also documented that poor infant feeding practice which is poor breastfeeding and poor complementary feeding contribute to $24 \%$ of infant deaths [13].

Poor complementary feeding practices means that many children continue to be vulnerable to irreversible outcomes of stunting, poor cognitive development, and significantly increased risk of infectious diseases leading to gastroenteritis, diarrhea and acute respiratory infection [7,14-16].

Exclusive breastfeeding for six months followed by timely initiation of appropriate complementary feeding with continued breastfeeding for the first year of life could avert 13 percent ( 1.3 million) of the more than 10 million deaths among children under 5 every year [17]. Regardless of the policy and strategies adopted by Ethiopian Ministry of Health, the change seen in the practice of the timely initiation of complementary feeding from 2005 to 2010 was insignificant.

The aim of this study was therefore: i) to determine the prevalence of the timely initiation of complementary feeding among 6 to 12 months age children in Northern Ethiopia; ii) to identify factors associated with the timely initiation of complementary feeding among 6 to 12 months age children in Northern Ethiopia.

\section{Methods}

\section{Study area and period}

This study was conducted in public health facilities found in Mekelle town, Northern Ethiopia. The town is the capital city of Tigray region and is located 783 Kilometers north of Addis Ababa, the capital of Ethiopia. Total population of Mekelle, as to 2007 census, was
177,090. Of the 9 public health facilities found in Mekelle zone, six public health facilities are found in the town in which this study was conducted. This study includes two hospitals, one regional and the other referral hospital, and 4 health centers which all give service for all the Mekelle town community members without restriction. The excluded facilities are, not providing service specifically for the town residents but to Mekelle zone, they were either newly built or found in areas recently included to Mekelle. The study was conducted from January to June 2011.

\section{Study design, population and sampling}

An institution based cross sectional was conducted. Mothers of infants aged from 6 months to one year in Mekelle town were the study population. The sample size for the study was calculated using single population proportion formula using the assumption that the proportion of mothers who initiate complementary feeding timely to their child to be 50\%, 95\% CI, 5\% marginal error, and $10 \%$ none response rate, a total of 422 mothers were required for the study.

The sampling unit was taken from each, six, public health institutions based on their predetermined patient flow rate. To allocate the study subjects, first the average numbers of clients who visit the under five outpatient department daily was estimated by referring client registration book/record for two weeks prior to data collection. Proportional allocation was made based on the possible number of patients that would be expected during the study period and systematic random sampling was employed to identify study participants. Sampling interval was determined by dividing the expected patient with in the study period by allocated sample size to each facility.

As to the simple observation made to assess the difference in characteristics of clients of the health centers and hospitals, utilization of the services was according to the physical proximity of facilities. In fact referral cases from different institutions come to hospitals which are not included in this study. Based on this fact, all institutions were considered as homogeneous.

\section{Data collection}

Data were collected by client exit interview from all mothers of infants aged between 6 months to one year attended under five clinics in all governmental health institution found in Mekelle town using structured questionnaire. Structured questionnaire which was originally prepared in English then translated to local language Tigrigna. The questionnaire was developed and refined on the basis of contents of peer review journals. Six female extension nursing students were recruited to collect data during working hours of the health institutions for the whole data collection period. 
Data quality control; Structure questionnaire was translated to local language and then back to English by two people for consistency. Pretest was made in 21 (5\%) mothers, in the study area, which was not included in the study to assess the content and approach of the questionnaire. One supervisor was recruited and training was given to data collectors and supervisor for two days on the objective, relevance of the study, confidentiality of information, respondent's right, about pre-test, informed consent and techniques of interview; after the investigators discuss deeply.

\section{Data analysis, presentation and interpretation}

Data were entered using EPI info version 3.5.1 statistical software and cleaning and analysis was made using SPSS version 16. Cleaning was made using frequencies. Univariate was done to describe dependent and independent variables; percentages, frequency distributions and measures of central tendency and measures of dispersion were used for describing data. Then binary logistic regression was made to see the crude significant relation of each variable with dependant variables. Finally, independent variables found significant were entered to multivariate logistic regressions to control the effect of confounding. Stepwise backward LR was used for multiple logistic regressions. Odds ratio with 95\% confidence interval to ascertain association between independent and dependent variable was used.

\section{Ethical considerations}

Ethical clearance was obtained from institutional review board of Addis Continental and Mekelle University. The offices of Tigray Region Health Bureau and Mekelle zonal health Department, the selected Health institutions were communicated with formal letters from the Mekelle University.

All the study participants was reassured that they would be anonymous. Names or any personal identifiers were not recorded. Respondents were clearly told about the study and the variety of information needed from them. They were given the chance to ask anything about the study and made free to refuse or stop the interview at any moment they want if that was their choice. After interview the importance of timely initiation of complimentary feeding was discussed with the respondents who had not had knowledge on complementary issues.

\section{Results}

\section{Socio-demographic characteristics of the mothers}

A total of 422 women having infant aged six months to one year were included in the study. There was $100 \%$ response rate. The overall mean age was $26.34 \pm 5.48$ (SD) with the range of $29(16,45)$. Majority of the respondents, $315(74.6 \%)$ were able to read and write. More than half of the mothers, $54.3 \%$, were unemployed. Three hundred twenty eight (77\%) were either married or were living with their partner. The vast majority of the respondent mothers, 363 (86\%), were orthodox Christians and more than $95 \%$ of the mothers were Tigrean in ethnicity (from the same region). Husbands of $83 \%$ (308/371) were employed or working for private sector; only $3(0.8 \%)$ were unemployed. The median family size was 4 . Among all respondents, 286 (67.8\%) had television and 310 (73.5\%) mothers had radio. Approximately 54\% of the respondents $(229 / 422)$ had both television and radio (Table 1$)$.

\section{Medical history of the mothers}

Three hundred sixty eight (87\%) mothers had antenatal care follow up at least once during the last pregnancy. About 70\% (294/422) of mothers had at least 4 visits as recommended. Near to $80 \%$ of all mothers had institutional delivery and 87 (20.6\%) mothers reported home delivery. About 70\% (294/422) of mothers had received postnatal care (Table 1).

\section{Breast feeding pattern}

Almost all of respondent mothers, 418 (99.1\%), had initiated breast feeding and this decreased to 410 (97.2\%) at the six month and majority, 96.4\%, were still breast feeding at the time of study. Only 15 (3.6\%) mothers had stopped breastfeeding before the child's sixth months of age.

Very few, only 4, mothers did not initiate breast-feeding at all; the main reasons were no breast milk (2), breast disease (1) and having HIV/AIDS (1). The supplemented foods were cow's milk and formula diet.

\section{Complementary feeding}

Of all mothers who had breastfeeding experience, 391 $(93.5 \%, \mathrm{n}=418)$ had started complementary feeding at the time of the interview with a range of 2 weeks to 11 months. Of all 19.7\% (83/422) of mothers initiated complementary feeding before the age of six months. And about $17.54 \%$ (74/422) mothers had initiated complementary feeding beyond six months. However, the prevalence of timely initiated complementary feeding at the age of six months was $62.8 \%$ (265/422, 95\% C.I: 58.1 , $67.31 \%)$. The majority of the respondents 310 (73.5\%) knew that a child was supposed to be exclusively breastfed for only six months, however, 48 (11.4\%) could not be sure about the right duration of exclusive breastfeeding and the other 64 (15.1\%) had a wrong idea about the right time of exclusive breast feeding.

The complementary food given by most of mothers was cereal based fluids $(46.5 \%, 181 / 389)$ followed by cow's milk (20.1\%, 78/389), formula milk (11.3\%, 44/389), family diet $(8.7 \%, 34 / 389)$ and the rest $(13.4 \%, 52 / 389)$ used the combination of two or more the above foods. 
Table 1 Socio-demographic and medical history of mothers, who had infant aged from six months to one year, attended public facilities in Mekelle town, from December 2010 - January 2011

\begin{tabular}{|c|c|c|c|}
\hline Variables & Category & Frequency (n) & Percentage \\
\hline \multirow[t]{4}{*}{ Age of the mother } & $15-19$ & 29 & 6.9 \\
\hline & $20-24$ & 141 & 33.4 \\
\hline & $25-29$ & 133 & 31.5 \\
\hline & $30+$ & 119 & 29.2 \\
\hline \multirow{5}{*}{$\begin{array}{l}\text { Educational status of } \\
\text { women }\end{array}$} & Illiterate & 112 & 26.5 \\
\hline & $1-4$ & 25 & 5.9 \\
\hline & $5-8$ & 93 & 22.0 \\
\hline & $9-10$ & 104 & 24.7 \\
\hline & $11+$ & 88 & 20.9 \\
\hline \multirow{5}{*}{$\begin{array}{l}\text { Husband education } \\
(\mathrm{n}=324)\end{array}$} & Illiterate & 98 & 23.2 \\
\hline & $1-4$ & 15 & 3.6 \\
\hline & $5-8$ & 73 & 17.3 \\
\hline & $9-10$ & 86 & 20.4 \\
\hline & $11+$ & 150 & 35.5 \\
\hline \multirow[t]{3}{*}{ Number of pregnancy } & $1-2$ & 275 & 65.2 \\
\hline & $3-5$ & 113 & 26.8 \\
\hline & $6+$ & 34 & 8.1 \\
\hline \multirow{2}{*}{$\begin{array}{l}\text { Months of pregnancy during } \\
\text { Initiation of ANC }(n=368)\end{array}$} & $1-3$ & 113 & 30.7 \\
\hline & $4+$ & 255 & 69.3 \\
\hline \multirow[t]{2}{*}{ Frequency of ANC $(n=368)$} & $1-4$ & 254 & 69.0 \\
\hline & $5+$ & 114 & 31.0 \\
\hline \multirow[t]{4}{*}{ Place of birth } & Home & 87 & 20.6 \\
\hline & Public facility & 313 & 74.2 \\
\hline & Health post & 4 & 0.9 \\
\hline & Private clinic & 18 & 4.3 \\
\hline \multirow{5}{*}{$\begin{array}{l}\text { Individual who assisted the } \\
\text { delivery }\end{array}$} & TBA/TTBA & 20 & 4.7 \\
\hline & Mother & 59 & 14.0 \\
\hline & Relatives & 19 & 4.5 \\
\hline & HEWs & 7 & 1.7 \\
\hline & $\begin{array}{l}\text { Health } \\
\text { professional }\end{array}$ & 317 & 75.1 \\
\hline
\end{tabular}

Approximately $25 \%$ of mothers had used bottle feeding either consistently or sometimes.

\section{Factors found associated with timely initiation of complementary feeding at sixth month}

After applying bivariate and multiple logistic regressions, five variables were found to be significantly associated with timely initiation of complementary feeding. These were education of mothers (greater than grade nine $(\mathrm{AOR}=2.361))$, mothers who were housewife or unemployed $(\mathrm{AOR}=2.347)$ ), mothers had at least one child
$(\mathrm{AOR}=2.344)$, and those mothers who made ANC follow up $(\mathrm{AOR}=2.845)$ and birth preparedness $(\mathrm{AOR}=2.816)$ were more likely to initiate complementary feeding timely at sixth month (Table 2).

\section{Discussion}

The result of our study revealed that timely initiation of complementary feeding is $62 \%$ with the median age of six months. House wife mothers, mothers and husbands education, ANC attendance, parity and birth preparedness were the factors found to increase initiation of complementary feeding on time.

The $62.8 \%$ prevalence we detected was higher than the national prevalence (51\%) [8]. It is also much higher than the study from Nairobi, (less than 10\%), Taiwan (50\%) and West Bengal, India (55.1\%) [10-12]. Our finding, although it is better than the one reported at national level and few other countries, it was still low as the remaining $38 \%$ of mothers did not start complementary feeding at the right time. This relatively higher prevalence of timely initiation of complementary feeding at six month can be explained by the expansion of the health extension workers in Ethiopia. The health extension workers among their other health activities are involved in continuous health education to the community which has contributed to high coverage of ANC attendance and health institutional delivery and also initiation of complementary feeding on time in Mekelle town. The median age of starting complementary feeding was six month, where as in a country like Ghana they started earlier at 5.4 months of the child age [18].

Not few mothers $(8.7 \%)$ used family diet as a complementary feeding while solid foods are not recommended at this age of infancy. Furthermore, majority of mothers used fluids as a complementary food that might dilute the nutritional contents and affect growth and development of children. Approximately $18 \%$ of children started complementary feeding late at seventh month or beyond, which would lead to macro and micro nutrient deficiency and serious nutritional problem, slows growth and predisposes to infectious disease that further exacerbates the nutritional status [7].

Mothers who had at least one child were 2.344 times higher in initiating complementary feeding at six months than mothers who had only one child, which is congruent with findings in other places [19]. Studies revealed that mothers who had at least one child have high levels of breastfeeding related knowledge, including appropriate time of initiating complementary feeding [20]. This may also be related to repeated exposure of health education during the previous pregnancies and the experience they gained through time, therefore repeated exposure to health education will have an impact in subsequent pregnancies. 
Table 2 Factors associated with timely initiation of complementary feeding among mothers who had infant aged from six months to one year, attended public facilities in Mekelle town, from December 2010 - January 2011

\begin{tabular}{|c|c|c|c|c|c|}
\hline \multirow[t]{2}{*}{ Variable } & \multirow[t]{2}{*}{ Category } & \multicolumn{2}{|c|}{ Complementary feeding timely } & \multirow[t]{2}{*}{$\operatorname{COR}^{\mathrm{a}}(95 \% \mathrm{Cl})$} & \multirow[t]{2}{*}{$\mathrm{AOR}^{\mathrm{b}}(95 \% \mathrm{Cl})$} \\
\hline & & Yes & No & & \\
\hline \multirow[t]{3}{*}{ Age of mothers } & $<=19$ & 13 & 16 & & \\
\hline & $20-29$ & 172 & 102 & $2.075(0.959,4.490)$ & $0.972(0.374,2.524)$ \\
\hline & $>30$ & 80 & 39 & $2.525(1.105,5.766)$ & $1.764(0.578,5.377)$ \\
\hline \multirow[t]{3}{*}{ Educational level of mother } & Illiterate & 54 & 58 & & \\
\hline & $1-8$ & 68 & 50 & $1.461(0.868,2.458)$ & $0.933(0.478,1.818)$ \\
\hline & $9-12+$ & 143 & 49 & $3.135(1.915,5.130)$ & $2.361(1.144,4.869)$ \\
\hline \multirow[t]{2}{*}{ Occupation of mother } & Employed & 111 & 82 & & \\
\hline & Jobless(housewives) & 154 & 75 & $1.517(1.020,2.256)$ & $2.347(1.404,3.921)$ \\
\hline \multirow[t]{2}{*}{ Marital status } & Not in union & 40 & 11 & & \\
\hline & Married/in union & 254 & 117 & $7.894(3.911,15.934)$ & $1.57(0.547,4.505)$ \\
\hline \multirow[t]{3}{*}{ Educational status of husband } & Illiterate & 32 & 66 & & \\
\hline & $1-8$ & 56 & 32 & $3.609(1.970,6.614)$ & $1.901(0.941,3.839)$ \\
\hline & $9-12+$ & 177 & 59 & $6.187(3.698,10.354)$ & $2.991(1.501,5.957)$ \\
\hline \multirow[t]{2}{*}{ Television ownership } & No & 60 & 76 & & \\
\hline & Yes & 205 & 81 & $3.206(2.096,4.904)$ & $0.969(0.512,1.834)$ \\
\hline \multirow[t]{2}{*}{ Radio ownership } & No & 54 & 58 & & \\
\hline & Yes & 211 & 99 & $2.289(1.471,3.558)$ & $1.444(0.854,2.442)$ \\
\hline \multirow[t]{2}{*}{ Number of live birth } & 1 & 100 & 78 & & \\
\hline & $>1$ & 165 & 79 & $1.629(1.093,2.429)$ & $2.344(1.438,3.822)$ \\
\hline \multirow[t]{2}{*}{ ANC follow up } & No & 13 & 41 & & \\
\hline & Yes & 252 & 116 & $6.851(3.536,13.276)$ & $2.845(1.240,6.528)$ \\
\hline \multirow[t]{2}{*}{ Postnatal care } & Yes & 67 & 61 & & \\
\hline & No & 198 & 96 & $1.878(1.229,2.869)$ & $0.860(0.492,1.505)$ \\
\hline \multirow[t]{2}{*}{ Planned child } & No & 55 & 57 & & \\
\hline & Yes & 210 & 100 & $2.176(1.401,3.381)$ & $1.052(0.589,1.885)$ \\
\hline \multirow[t]{2}{*}{ Place of delivery } & Out of health facility & 40 & 51 & & \\
\hline & Health facility & 225 & 106 & $2.706(1.685,4.348)$ & $0.720(0.270,1.920)$ \\
\hline \multirow[t]{2}{*}{ Assistant of the delivery } & Non professional & 48 & 57 & & \\
\hline & Professional & 217 & 100 & $2.577(1.641,4.046)$ & $1.253(0.690,2.275)$ \\
\hline \multirow[t]{2}{*}{ Birth preparedness } & No & 22 & 57 & & \\
\hline & Yes & 243 & 100 & $6.296(3.653,10.850)$ & $2.816(1.459,5.437)$ \\
\hline \multirow[t]{2}{*}{ Knows optimal BF } & No & 175 & 130 & & \\
\hline & yes & 90 & 27 & $2.476(1.523,4.027)$ & $1.426(0.806,2.522)$ \\
\hline
\end{tabular}

${ }^{\mathrm{a}}$ COR Crude Odds Ratio.

${ }^{b}$ AOR Adjusted Odds Ratio.

A higher maternal educational level, high school and above (AOD $=2.361$, was noted to increase timely initiation of complementary feeding; similar findings were observed by other studies in Nairobi, Kenya [15], Hong Kong [19], Belgium [21], and Bavaria, Germany [22]. This can be explained that improved maternal education enhances mothers' understanding and appreciation of the demands and benefits of introducing complementary feeding timely, and empowers them to resist external interferences and pressures.

A higher husband educational level, high school and above (AOD $=2.991$ ), was also noted to favor timely initiation of complementary feeding as education is believed to enable the husbands to understand their wives and provide help and approval to what mothers would like to do to keep the child healthy. 
Antenatal care attendance seems to have an impact, $\mathrm{AOR}=2.845$, on exclusive breastfeeding for the first six months and initiating complementary feeding at the six months. Therefore, ANC is very important to also deliver other maternal health related messages to women.

House-wife mothers were more likely to initiation of complementary feeding timely which was in line with finding in other places [22]. This can be because the housewives usually stay at home and would not be obliged like mothers who are working to wean early to go to work.

Mothers who made birth preparedness were 2.816 times more likely to initiate complementary feeding at six month than those who do not. This might enable mothers to arrange conditions which could help them initiate complementary feeding timely.

Though, some other findings revealed that being older age is favorable to initiate complementary feeding timely $[19,21,22]$, in this study age had no association with timely initiation of complementary feeding, similar to the finding from Nigeria [23].

\section{Conclusion}

Almost two-third of mothers initiated complementary feeding at sixth month of child age that is relatively higher prevalence than other countries. In order to reduce the high infant mortality this level has to be increased since $38 \%$ of the mothers are still not starting complementary feeding at six months. Education status of the mother and the husband, occupation of the mother, number of children, antenatal care follow up and birth preparedness are the predictors of timely initiation of complementary feeding.

We recommend,

- The high ANC attendance in this area is also accompanied with high institutional delivery and timely imitation of the complementary feeding unlike other places areas within the country. Therefore, it is important to further analyze what contributed to this achievement in this area so that it can be tried in other parts of the country.

- The mass media could result in positive changes if child feeding messages were transmitted; as all are urban women, who has at least one means of source of information (Radio or/and TV) and are more likely to listen to and be influenced by it.

- Mothers who are illiterate and completed only primary school need more attention.

- All mothers must be encouraged to make antenatal care follow up and birth preparedness.

The authors declare that they have no competing interests.

\section{Authors' contributions}

AS: Initiated the research, wrote the research proposal, conducted the research, did data entry and analysis and wrote the manuscript. MD: Involved in the write up of the proposal, write up of the manuscript. YB: Involved in the write up of the proposal, write up of the manuscript. All authors read and approved the final manuscript

\section{Authors' information}

Ashenafi Shumye: BSc, MPH.

Meaza Demissie: MD, MPH, PhD, Assoc. Prof. Public Health, at Addis Continental institute of public Health.

Yemane Berhane: MD, PhD, Prof. of Epidemiology and Public Health, at Addis Continental institute of public Health.

\section{Acknowledgements}

We are thankful to all respondents for their willing to participate in the study as it is through their cooperation that we have been able to write this report. We are also grateful for the heads of all the six health institutions for allowing us to collect data.

The data collectors are acknowledged for their effort in collecting the information. We also would like to thank to Mekelle University for the financial support and Addis Continental Institute of Public Health for technical assistance and approving this study.

\section{Author details}

${ }^{1}$ Public Health Department, College of Health Sciences, Mekelle University, Mekelle, Ethiopia. ${ }^{2}$ Addis Continental Institute of Public Health, Addis Ababa, Ethiopia.

Received: 7 February 2013 Accepted: 31 October 2013

Published: 6 November 2013

\section{References}

1. World Health Organization: Complementary Feeding: Summary of Guiding Principles. Report of the Global Consultation, 10-13 December 2001. Geneva, Switzerland: World Health Organization; 2002.

2. Federal Ministry of Health, Family Health Department Ethiopia: National strategy for infant and young child feeding. Addis Ababa: Federal Ministry of Health, Family Health Department Ethiopia; 2004.

3. Martines J, Paul VK, Bhutta ZA, Koblinsky M, Soucat A, Walker N, et al: Neonatal survival: a call for action. Lancet 2005, 365:1189-1197.

4. Singer PA, Ansett S, Sagoe-Moses I: What could infant and young child nutrition learn from sweatshops? BMC Public Health 2011, 11:276.

5. PAHO/WHO: Guiding Principles for Complementary Feeding of the Breastfed Child. Division of Health Promotion and Protection. Food and Nutrition Program. Washington/Geneva: Pan American Health Organization/World Health Organization; 2003.

6. World Health Organization: Global strategy for infant and young child feeding. Geneva: World Health Organization; 2003:41.

7. WHO and UNICEF: Complementary feeding of young children in developing countries: a review of current scientific knowledge. Geneva: World Health Organization, WHO/NUT/98; 1998:1.

8. Imdad A, Yakoob MY, Bhutta ZA: Impact of maternal education about complementary feeding and provision of complementary foods on child growth in developing countries. BMC Public Health 2011, 11(Suppl 3):S25.

9. Central Statistical Agency [Ethiopia] and ORC Macro: Ethiopia Demographic and Health Survey 2011. Addis Ababa, Ethiopia and Calverton, Maryland, USA: Central Statistical Agency and ORC Macro; 2012.

10. Kimani-Murage EW, Madise NJ, Fotso JC, Kyobutungi C, Mutua MK, Gitau TM, Yatich N: Patterns and determinants of breastfeeding and complementary feeding practices in urban informal settlements, Nairobi Kenya. Kimani-murage et al. BMC Public Health 2011, 11:396.

11. Lin JR, Tzeng MS, Kao MD, Yang YH, Pan W: Practice to introduce complementary foods to infants in Taiwan - changes from 1997 to 2008. Asia Pac J Clin Nutr 2011, 20(2):337-345.

12. Sinhababu A, Mukhopadhyay DK, Panja TK, Saren AB, Mandal NK, Biswas AB: Infant- and young child-feeding practices in Bankura District, West Bengal, India. J Health Popul Nutr 2010, 28(3):294-299. 
13. Ethiopia Public Health Training Initiative: Essential Nutrition Actions to Improve the Nutrition of Women and Children in Ethiopia, Including Under Situations of Emergencies and HIV/and AIDs; Training Manual, Linkages. Addis Ababa: Ethiopia Public Health Training Initiative; 2004

14. Saha KK, Frongillo EA, Alam DS, Ariffen SE, Persson LA, Rasmussen KM: Appropriate infant feeding practices result in better growth of infants and young children in rural Bangladesh. Am J Clin Nutr 2008, 87:1852-1859.

15. World Health Organization, Division of Family Health: The prevalence and duration of breastfeeding in urban population of Chandigarh during adecade. Indian Pediator 1987, 24:879-887.

16. Hop LT, Gross R, Giay T, Sastroamidjojo S, Schultink W, Lang NT: Premature complementary feeding is associated with poorer growth of Vietnamese children. J Nutr 2000, 130:2683-2690.

17. Prieto CR, Cardenas H, Croxatto HB: Variability of breast sucking, associated milk transfer and the duration of lactational amenorrhea. J Reprod Fertil 1999, 115:193-200.

18. WHO multicentre growth reference study group, de Onis M: Complementary feeding in the WHO multicentre growth reference study. Acta Paediatr 2006, 95:27-37.

19. Tarrant M, Fong DYT, Wu KM, Lee ILY, Wong EM, Sham A, et al: Breastfeeding and weaning practices among Hong Kong mothers: a prospective study. BMC Pregnancy Childbirth 2010, 10:27.

20. Laantera S, Polkki T, Ekstrom A, Pietila AM: Breastfeeding attitudes of Finnish parents during pregnancy. BMC Pregnancy Childbirth 2010, 10:79.

21. Sonia S, Veit G, Silvia S, Veronica L, Francoise M, Anna S, et al: Introduction of complementary feedong in 5 European countries. $J$ Pediatr Gastroenterol Nutr 2010, 50(1):92-98.

22. Barbara R, Martina K, Ursula S, Berthold VK, Hermann F: Infant feeding practices and associated factors through the first 9 months of life in Bavaria, Germany. J Pediatr Gastroenterol Nutr 2009, 49(4):467-473.

23. Kuti $\mathrm{O}$, Adeyemi AB, Owolabi AT: Breast-feeding pattern and onset of menstruation among Yoruba mothers of South-west Nigeria. Eur I Contracept Reprod Health Care 2007, 12(4):335-339.

doi:10.1186/1471-2458-13-1050

Cite this article as: Shumey et al:: Timely initiation of complementary feeding and associated factors among children aged 6 to 12 months in Northern Ethiopia: an institution-based cross-sectional study. BMC Public Health 2013 13:1050.

\section{Submit your next manuscript to BioMed Central and take full advantage of:}

- Convenient online submission

- Thorough peer review

- No space constraints or color figure charges

- Immediate publication on acceptance

- Inclusion in PubMed, CAS, Scopus and Google Scholar

- Research which is freely available for redistribution 